\title{
Synthesis of Gadolinium Nanoparticles as a CT-Scan Contrast Agent with Pulse Laser Ablation Method
}

\author{
Adilla Luthfia*1, Iis Nurhasah², Ali Khumaeni ${ }^{2}$
}

${ }^{* 1}$ Master of Physics, Department of Physics, Faculty of Science and Mathematics, Diponegoro University, Prof. Soedharto St, SH, Tembalang, Semarang, Indonesia

${ }^{2}$ Department of Physics, Faculty of Science and Mathematics, Diponegoro University, Prof. Soedharto St, SH, Tembalang, Semarang, Indonesia

\begin{abstract}
Article Info

Volume 8, Issue 3

Page Number : 01-05

Publication Issue

May-June-2021

\section{Article History}

Accepted : 12 June 2021

Published : 22 June 2021

The use of iodine contrast agents on CT Scan clinically shows a short-term blood circulation, non-specific biodistribution and causes side effects on kidneys. Nanoparticles have a longer half-time vascular than molecular contrast agents so it can be observed for a longer time after injection. Gadolinium ( $\mathrm{Z}=64)$ has a higher atomic number and X-ray absorbance coefficient than iodine $(Z=53)$ and does not have the negative effect on kidneys. The Gd nanoparticles development as a CT Scan contrast agent has potential to give more effectiveness than iodine contrast agents. In this study, Gd nanoparticles were synthesized using pulsed laser ablation method with wavelength $1064 \mathrm{~nm}$, energy $45 \mathrm{~mJ}$, and pulse width $7 \mathrm{~ns}$. The ablation process was carried out for 180 minutes with repetition rate of $10 \mathrm{~Hz}$ and $15 \mathrm{~Hz}$. The formation of Gd Nanoparticles was analyzed using UV-Vis spectrophotometer and FTIR (Fourier-Transform Infrared Spectroscopy). Testing the ability of Gd nanoparticles as a contrast agent was done in the diagnosis of head and abdomen using a CT Scan GE CT Optima 580 RT type 229156-3. UV-Vis spectrophotometer analysis showed that Gd nanoparticles had high absorbance at the wavelength less than $250 \mathrm{~nm}$ which indicated the formation of $\mathrm{Gd} 2(\mathrm{OH}) 3$ compounds. The repetition rate difference in ablation process resulted in the same concentration of $\mathrm{Gd}$ nanoparticles with different contrasts. Repetition rate of $10 \mathrm{~Hz}$ produced $\mathrm{Gd}$ nanoparticles with $\mathrm{HU}$ greater than repetition rate of $15 \mathrm{~Hz}$ and closer to $\mathrm{HU}$ of iodine. The results indicate that $\mathrm{Gd}$ nanoparticles can be used as a CT Scan contrast agent.
\end{abstract}

Keywords : Nanoparticles, gadolinium, contrast agent CT Scan, pulse laser ablation method 


\section{INTRODUCTION}

Computed Tomography Scan (CT Scan) is widely used in radiodiagnostics due to its relatively lower price compared to MRI and its ability to produce efficient images. Different body tissues have different mass attenuation coefficient. In result, the $\mathrm{X}$-rays that pass through the human body will form contrasts in the image. CT Scan can distinguish bone and tissue easily but it is still difficult for soft tissues such as muscles, organs, and tumors because they have nearly the same mass attenuation coefficient. As a solution, contrast agents can be used on CT scan imaging. Currently, most widely used CT scan contrast agents are iodinebased molecules. However, in clinical practice it is known that iodine has a short-term existence in blood circulation, non-specific bio-distribution, and renal toxicity [1]. Nanoparticles have the potential to provide better image contrast than iodine compounds and have a longer vascular half-life than molecular contrast agents. As a result, nanoparticle contrast agents can be monitored for a longer period of time after being injected into living organisms [2].

An alternative to iodine as a contrast agent is the use of materials containing high atomic number metals [3]. Gadolinium $(Z=64, \mathrm{k}$-edge $=50 \mathrm{keV})$ has a higher atomic number and a higher k-edge than iodine $(\mathrm{Z}=$ 53 , $\mathrm{k}$-edge $=33 \mathrm{keV}$ ) which is more suitable with the post-filtration spectrum intensity of the energy peak that has generated during CT scan between 50-140 $\mathrm{kVp}$ [4]. More than that, gadolinium has been shown to have no negative effect on the kidneys [5]. High atomic number metal nanoparticles have the character of increasing the radiation dose per unit mass [6]. Thus, it is hoped that a small concentration of nanoparticles can provide more effectiveness than the use of iodine contrast agents. Various potentials of nanoparticles and gadolinium encourage us to conduct research on the synthesis of gadolinium $(\mathrm{Gd})$ nanoparticles as CT contrast agents.
The formation of metal nanoparticles in the medical field needs to pay attention to purity. High purity can reduce tissue toxicity [7]. Pulsed laser ablation method in liquid medium can produce nanoparticles with high purity. This synthesis method is carried out using laser energy that is fired at the target metal in liquid medium. The greater the laser energy used, the smaller the size of nanoparticles and the greater the repetition rate used, the larger the size of the nanoparticles produced [8]. We used a pulsed laser $\mathrm{Nd}$ :YAG by varying the repetition rate so that we can know its effect on the effectiveness of $\mathrm{Gd}$ nanoparticles as a contrast agents. The effectiveness can be seen from the value of the Hounsfield Unit $(\mathrm{HU})$ from the CT Scan image.

\section{METHODS AND MATERIAL}

The synthesis of Gd nanoparticles was carried out using a pulsed Nd:YAG laser with a wavelength of $1064 \mathrm{~nm}$, energy of $45 \mathrm{~mJ}$, and pulse width of $7 \mathrm{~ns}$. Gadolinium metal was placed in a $25 \mathrm{ml}$ glass petri dish containing $15 \mathrm{ml}$ of aquadest. The synthesis used a petri dish in order to keep the space in aquadest so that the nanoparticles formed, remained in there. The Nd:YAG laser beam was directed by a convex lens (focal length $3 \mathrm{~cm}$ ) to scrape the gadolinium metal surface at the bottom of the petri dish. Gd nanoparticles with $0.006 \mathrm{mg} / \mathrm{ml}$ concentration were made with repetition rates of $10 \mathrm{~Hz}$ and $15 \mathrm{~Hz}$, for 180 minutes.

The Gd nanoparticles were characterized using a UVVis spectrophotometer at $200 \mathrm{~nm}-800 \mathrm{~nm}$ wavelength and FTIR (Fourier-Transform Infrared Spectroscopy) to find out the functional groups. The next step was testing the Gd nanoparticles as a CT Scan contrast agents. At this stage, there were 3 samples, namely nanoparticles $\mathrm{Gd} 0.006 \mathrm{mg} / \mathrm{ml} 10 \mathrm{~Hz}$, nanoparticles Gd $0.006 \mathrm{mg} / \mathrm{ml} 15 \mathrm{~Hz}$, and iodine solution $37 \mathrm{mg} / \mathrm{ml}$ for comparison. The test was carried out by placing each sample into a $2 \mathrm{ml}$ vial 
tube and arranged in the CT Scan's target field of GE CT Optima 580 RT type 229156-3. Scans were performed for head and abdomen diagnosis, then the images obtained were processed using RadiAnt DICOM Viewer software to determine the HU value in each sample with head and abdomen diagnosis.

\section{III.RESULTS AND DISCUSSION}

Laser ablation method could synthesize colloidal Gd nanoparticles from pure $\mathrm{Gd}$ plates using an $\mathrm{Nd}$ :YAG laser (1064 nm, $40 \mathrm{~mJ}, 7 \mathrm{~ns})$ in aquadest. From the synthesis that carried out, it was known that colloidal Gd nanoparticles formed had cloudy white appearance after 180 minutes of ablation. The Gd nanoparticles were analyzed using Uv-Vis and FTIR. The absorbance spectrum of Gd nanoparticles from UV-Vis analysis is shown in Fig. 1. It can be seen that Gd nanoparticles produced high absorption at a wavelength of less than $250 \mathrm{~nm}$. The graph shows that the higher the repetition rate, the higher the absorbance of Gd nanoparticles.

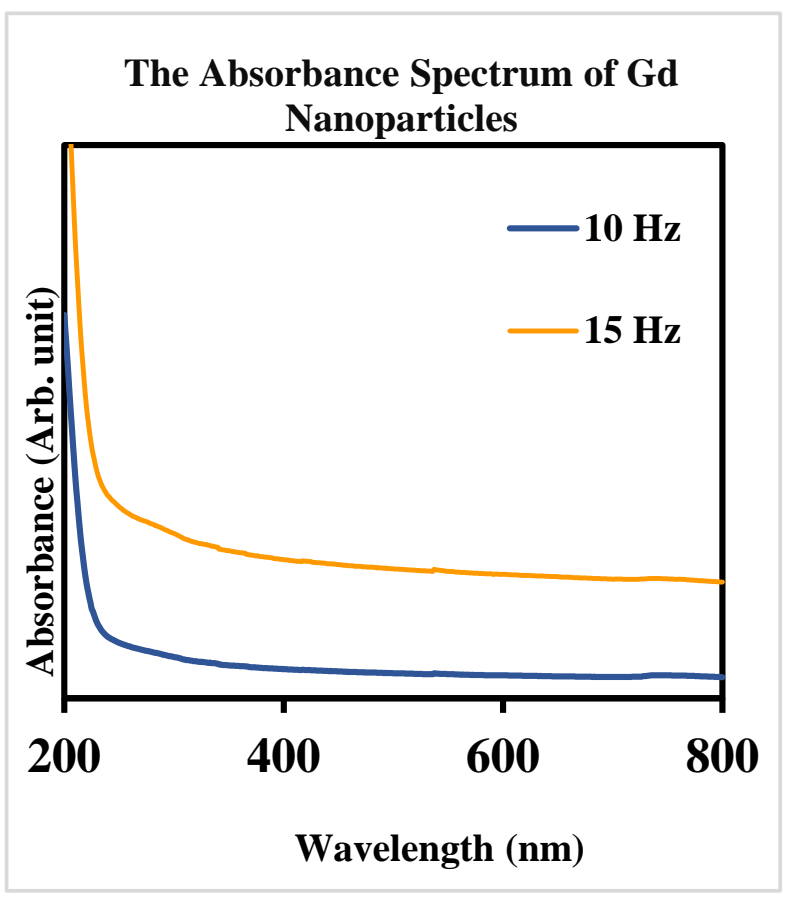

Figure 1. The Absorbance Spectrum of Gd Nanoparticles from Pulsed Laser Ablation Method in Aquadest.
Gadolinium compounds in $\mathrm{Gd}$ nanoparticles were analyzed by FTIR. The FTIR spectrum of Gd nanoparticles in aquadest with a repetition rate of 10 $\mathrm{Hz}$ and $15 \mathrm{~Hz}$ is shown in Fig. 2 (a) and 2 (b).

FTIR Spectrum of Gd Nanoparticles $10 \mathrm{~Hz}$

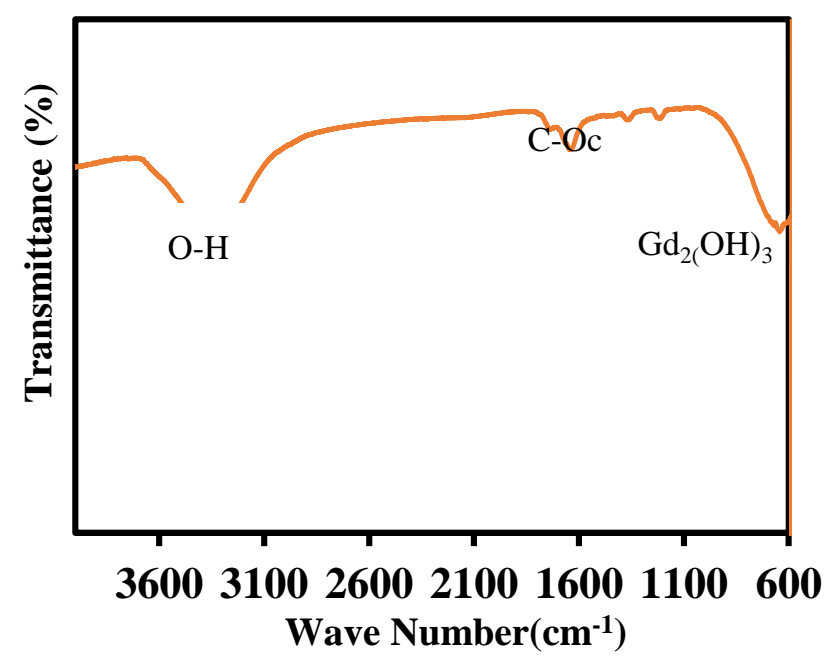

(a)

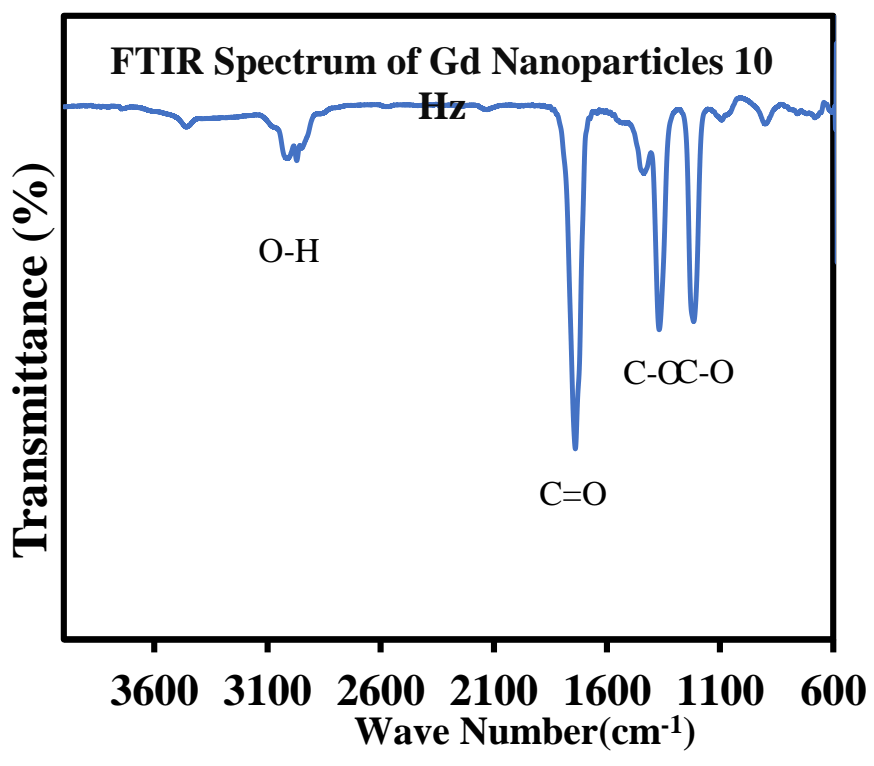

(b)

Figure 2. FTIR Spectrum of Gd Nanoparticles in Aquadest Repetition Rate (a) $10 \mathrm{~Hz}$ dan (b) $15 \mathrm{~Hz}$

Figure 2 (a) above shows several absorption peaks, namely $643 \mathrm{~cm}^{-1}, 1648 \mathrm{~cm}^{-1}$, and $3403 \mathrm{~cm}^{-1}$. The absorption peak of $643 \mathrm{~cm}^{-1}$ indicated the presence of colloidal Gd nanoparticles. At a wave number of 1648 
$\mathrm{cm}^{-1}$, a functional group of $\mathrm{C}-\mathrm{O}$ bonds was observed because the $\mathrm{pH}$ of $\mathrm{Gd}$ nanoparticles was 5 (acid) [9], while the peak widen at $3403 \mathrm{~cm}^{-1}$ it indicated the presence of $\mathrm{H}-\mathrm{O}$ bonds from the $\mathrm{H}_{2} \mathrm{O}$ molecule [10].

In Figure $2(\mathrm{~b})$ there are 4 successive peaks at the wave number of $3012 \mathrm{~cm}^{-1} ; 1739,75 \mathrm{~cm}^{-1} ; 1369 \mathrm{~cm}^{-1}$; and $1216,75 \mathrm{~cm}^{-1}$. The peak of $3012 \mathrm{~cm}^{-1}$ indicates the presence of $\mathrm{O}-\mathrm{H}$ functional group. Wave number $1739,75 \mathrm{~cm}^{-1}$ shows that there is a $\mathrm{C}=\mathrm{O}$ bond. $\mathrm{C}-\mathrm{O}$ bonds were detected $1369 \mathrm{~cm}^{-1}$, dan $1216,75 \mathrm{~cm}^{-1}$. In aquadest, $\mathrm{Gd}$ nanoparticles tend to form $\mathrm{Gd}_{2}(\mathrm{OH})_{3}$ compounds due to the presence of $\mathrm{Gd}-\mathrm{O}-\mathrm{H}$ vibration bonds [11]. When compared between Fig. 2 (a) and 2 (b) it can be seen that the $10 \mathrm{~Hz}$ Gd nanoparticles have fewer carbon bonds. This indicated that the purity of Gd nanoparticles $10 \mathrm{~Hz}$ was higher than 15 Hz.

HU values in CT Scan images were analyzed using RadiAnt Dicom Viewer software. Table 1 shows the HU values of the three samples in the head and abdomen diagnosis. It is known that the $\mathrm{HU}$ of $\mathrm{Gd}$ nanoparticles $10 \mathrm{~Hz}$ has a higher value than $15 \mathrm{~Hz}$.

Table 1. HU Value of Gd Nanoparticles and Iodine

\begin{tabular}{llcc}
\hline No & Sample & \multicolumn{2}{c}{ HU } \\
\cline { 3 - 4 } & & Head & Abdomen \\
\hline 1. & Gd $10 \mathrm{~Hz}$ & 26 & 14 \\
\hline 2. & Gd $15 \mathrm{~Hz}$ & 24 & 5 \\
\hline 3. & Iodine & 33 & 11 \\
\hline
\end{tabular}

Between the two Gd samples, the HU nanoparticles Gd $10 \mathrm{~Hz}$ had a value close to iodine. It is known with a smaller repetition rate (result size of greater nanoparticles) can produce Gd nanoparticles with $\mathrm{HU}$ value close to iodine. This shows that a small Gd concentration value of 0.006 is able to have $\mathrm{HU}$ value that is close to iodine $37 \mathrm{mg} / \mathrm{ml}$. This is because Gd has a higher $\mathrm{X}$-ray absorbance coefficient than iodine [12].

\section{IV.CONCLUSION}

The Gd nanoparticles with high purity were successfully produced using pulsed laser ablation method in aquadest from Gd metal. Gd nanoparticles have high absorbance at wavelengths less than 250 $\mathrm{nm}$. In aquadest, $\mathrm{Gd}$ nanoparticles tend to form $\mathrm{Gd}_{2}(\mathrm{OH})_{3}$ compounds. The results showed that $\mathrm{Gd}$ nanoparticles with a small concentration (0.006 $\mathrm{mg} / \mathrm{ml}$ ) and a repetition rate of $10 \mathrm{~Hz}$ had a $\mathrm{HU}$ value close to the HU iodine value of $37 \mathrm{mg} / \mathrm{ml}$. Thus, $\mathrm{Gd}$ nanoparticles can be used as contrast agents for CT scans with small concentrations.

\section{REFERENCES}

[1]. He W, Ai K, Lu L. 2015. Nanoparticulate X-ray CT Contrast Agents. Sci China Chem. DOI:10.1007/s11426-015-5351-8.

[2]. Alric C, Taleb J, Le DG, Mandon C, Billotey C, Le MA, Brochard T, Vocanson F, Janier M, Perriat P, Roux S, Tillement O. 2008. Gadolinium Chelate Coated Gold Nanoparticles as Contrast Agents for both X-ray Computed Tomography and Magnetic Resonance Imaging. J Am Chem Soc. DOI: 10.1021/ja078176p

[3]. Bongers M, Christoph S, Krauss B, Claussen C, Nikolaou K, Thomas C. 2017. Potential of Gadolinium as Contrast Material in Second Generation Dual Energy Computed Tomography - An Ex Vivo Phantom Study. Clinical Imaging. DOI:10.1016/j.clinimag.2017.02.005.

[4]. Flohr T. "Written communication Siemens Medical Systems", Erlangen, Germany.

[5]. Schieda N, Maralani PJ, Hurrell C, Tsampalieros AK, Hiremath S. 2017. Updated Clinical Practice Guideline on Use of Gadolinium-Based Contrast Agents in Kidney Disease Issued by the Canadian Association of Radiologists. 
Canadian Association of Radiologists Journal. DOI:10.1016/j.carj.2019.04.001

[6]. Kobayashi K, Usami N, Porcel E, Lacombe S, Le Sech C. 2010. Enhancement of Radiation Effect by Heavy Elements. Mutation Research/Reviews in Mutation Research. DOI:10.1016/j.mrrev.2010.01.002

[7]. Lintang IN, Nurhasanah I, Khumaeni A. 2019. Synthesis of gadolinium Nanoparticles Using Pulse Laser Ablation Method. International Conference on Science and Applied Science (ICSAS). DOI:10.1063/1.5141615.

[8]. Amendola V and Meneghetti M. 2009. Laser Ablation Synthesis in Solution and Size Manipulation of Noble Metal Nanoparticles. Physical Chemistry Chemical Physics. DOI: 10.1039/b900654k.

[9]. Zhang J, Chaker M, Ma D. 2016. Pulsed Laser Ablation based Synthesis of Colloidal Metal Nanoparticles for Catalytic Applications. Journal of Colloid and Interface Science. DOI: 10.1016/j.jcis.2016.07.050.

[10]. Zou G, Run L, Weixiang C, Zhude X. 2007. Preparation and Characterization of Lamellarlike $\mathrm{Mg}(\mathrm{OH}) 2$ Nanostructures via Natural Oxidation of $\mathrm{Mg}$ Metal in Formamide/Water Mixture. Materials Research Bulletin. DOI: 10.1016/j.materresbull.2006.09.008

[11]. Chen F, Zhang XH, Hu XD, Zhang W, Zeng R, Liu PD, Zhang HQ. 2016. Synthesis and Characteristics of Nanorods of Gadolinium Hydroxide and Gadolinium Oxide. Journal of Alloys and Compounds. DOI:10.1016/j.jallcom.2015.12.225.

[12]. Mowat P, Mignot A, Rima W, Lux F, Tillement O, Roulin C, Dutreix M, Bechet D, Huger S, Humbert L, Barbei-Heyob M, Aloy MT, Armandy E, Rodriguez-Lafrasse C, Le Duc G, Roux S, Perriat P. 2011. In vitro Radiosensitizing Effects of Ultrasmall Gadolinium Based Particles on Tumour Cells,
Journal Nanoscience Nanotechnolgy. DOI: 10.1166/jnn.2011.4725.

\section{Cite this article as :}

Adilla Luthfia, Iis Nurhasah, Ali Khumaeni, " Synthesis of Gadolinium Nanoparticles as a CT-Scan Contrast Agent with Pulse Laser Ablation Method", International Journal of Scientific Research in Science and Technology(IJSRST), Print ISSN : 2395-6011, Online ISSN : 2395-602X, Volume 8, Issue 3, pp.807811, May-June-2021. Available at doi : https://doi.org/10.32628/IJSRST2183173 Journal URL : https://ijsrst.com/IJSRST2183173 